Artículo de reflexión

Cuestiones de Filosofía

ISSN: 0123-5095

E-ISSN: 2389-9441

Vol. $7-\mathrm{N}^{\mathrm{o}} 28$

Enero - junio, año 2021

pp. 133-152

\title{
Memoria, olvido y trascendencia: dimensiones de la historicidad en la Segunda consideración intempestiva ${ }^{1}$
}

\author{
Memory, forgetfulness and transcendence: \\ dimensions of historicity in the Second untimely \\ consideration
}

Oscar Javier Jiménez Pirajan ${ }^{2}$ Grupo de investigación EREIGNIS, Colombia

Recepción: 20 de octubre del 2020

Evaluación: 12 de diciembre del 2020

Aceptación: 30 de enero del 2021

1 Este artículo ha sido desarrollado como parte del trabajo del grupo de investigación EREIGNIS.

2 Magister y Especialista en Filosofía contemporánea de la Universidad de San Buenaventura. Filósofo por la Universidad Abierta y a Distancia (UNAD).

Correo electrónico: jimenez.74@gmail.com 


\title{
Resumen
}

El artículo presenta una reflexión en torno a la historicidad en lo referente a la vivencia y conciencia del ser temporal, a partir del análisis de dicho concepto en la Segunda consideración intempestiva de Nietzsche. Se intenta describir y delimitar cada una de las dimensiones en las que Nietzsche analizó la vivencia humana de la historia en busca del entendimiento de la experiencia histórica y temporal de la vida. Para ello hace falta entender previamente el carácter intempestivo del pensamiento filosófico, así como el papel del olvido como potencia creadora fundamental para la vida. La presente interpretación propone la idea del pensar filosófico como síntesis de la experiencia histórica, de sus dimensiones y posibles modos de asumir y vivir la historia. Dicha síntesis entre lo que se olvida, lo que se recuerda y lo que trasciende de la experiencia histórica constituye, en consecuencia, el carácter propio de la filosofía como un modo particular de vivir.

Palabras clave: historia, cultura, olvido, memoria, vida.

\begin{abstract}
The article presents a reflection on historicity in relation to the experience and consciousness of the temporal being, based on the analysis of said concept in Nietzsche's Second untimely consideration. An attempt is made to describe and delimit each of the dimensions in which Nietzsche analysed the human experience of the history in search of an understanding of the historical and temporal experience of life. Therefore, it is necessary to previously understand the untimely nature of philosophical thought, as well as the role of forgetting as a creative power, fundamental for life. The present interpretation suggests the idea of philosophical thought as a synthesis of historical experience, of its dimensions and possible ways of assuming and living history. Such synthesis between what is forgotten, what is remembered and what transcends historical experience constitutes, consequently, the proper character of philosophy as a particular way of living.
\end{abstract}

Keywords: history, culture, forgetfulness, memory, life. 


\section{El valor de la historia para la vida}

En la Segunda consideración intempestiva: de la utilidad y los inconvenientes de la historia para la vida, Nietzsche expone un análisis de la historicidad en tanto carácter fundamental de la vida, y de la actitud del hombre frente a su historia como elemento determinante de la cultura. Esta visión del fenómeno histórico a partir de tres dimensiones de la experiencia temporal (historicidad), a las que designa como histórica, ahistórica y suprahistórica, responde a un problema esencial para el joven Nietzsche: el exceso de conocimiento histórico en la formación de los individuos; problema que designa como enfermedad histórica y decadencia general de los valores que definen a un pueblo o civilización, es decir, de su cultura. Dicha enfermedad es un problema que concierne a la forma de ver y representar la realidad, inherente a la vida en tanto experiencia del tiempo. Este análisis propicia reflexiones que trascienden el problema de lo histórico, y tiene que ver con el propósito mismo de la filosofía como actividad vital para la cultura y el sentido de la experiencia humana. Como señaló Heidegger en Ser y tiempo, "(...) la clasificación de Nietzsche no está hecha al azar. El comienzo de su Segunda consideración permite conjeturar que él comprendía más de lo que daba a conocer" (Heidegger, 2012, p. 409).

¿Hasta qué grado el conocimiento histórico aporta utilidad y valor a un organismo (hombre, pueblo, civilización)? ¿En qué medida el conocimiento del pasado es perjudicial para la salud de la cultura? “(...) según las palabras de Goethe, hemos de detestar seriamente la enseñanza sin vivificación, el saber en el que se paraliza la actividad, la historia como lujo y preciosa superabundancia de conocimientos" (Nietzsche, 2011, p. 695). La relación del hombre con su pasado (memoria y olvido), es determinante para su horizonte vital y el modo en que asume la vida: "Este es un problema cultural: conocimiento y vida" (Nietzsche, 2010, p. 381) . $^{3}$

De la conciencia de su temporalidad, que en esencia le distingue del animal, depende la actitud del hombre ante el presente y la misma vida. Sin embargo, hay una medida del saber - del saber histórico, de todo saber objetivo- que excede aquel que hace falta para vivir. Que el saber histórico predetermina e influye en la experiencia del vivir, es una noción de la mayor importancia para

3 Se ha señalado cómo, justamente, la cultura y su relación con la vida es un problema esencial del pensamiento nietzscheano, de marcada presencia en la producción de los primeros años (Sánchez Meca, 2013, p. 47). 
el estudio de la filosofía de Nietzsche, quien, siguiendo con Heidegger, hace con ello un descubrimiento esencial: "La posibilidad de que el saber histórico

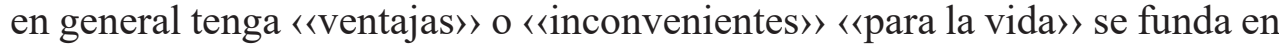
que ésta es histórica en la raíz misma de su ser y que, por consiguiente, en cuanto fácticamente existente, ya siempre se ha decidido por una historicidad propia o impropia" (Heidegger, 2012, p. 409).

El conocimiento debería ser útil a la vida y estar subordinado a ella y a su servicio. Un exceso de saber, por el contrario, puede empobrecer la praxis de la vida, la propia experiencia de vivir. El lujo, la superabundancia de conocimientos, resultan perjudiciales para la vida y la cultura cuando paralizan su actividad, su fuerza creativa: cuando el peso del pasado y de la historia impiden al presente hacer su propia historia y éste enferma de sentido histórico. Se requiere una medida justa de conocimiento histórico para vivificar y estimular el organismo a la acción: "Es cierto que necesitamos historia", pero “(...) la necesitamos para vivir y para actuar, no para apartarnos cómodamente de la vida y de la acción, ni para adornar una vida egoísta y una acción cobarde y mala" (Nietzsche, 2011, p. 696).

Si la vida se subordina a la búsqueda y acumulación, ya no de saber, sino de conocimientos objetivos, de información, y a su exceso, la cultura se empobrece "El impulso de conocimiento histórico -su fin es comprender al hombre en el devenir, dejar aquí a un lado también lo milagroso. Este impulso priva al impulso de cultura de su máxima fuerza: el conocimiento es un puro lujo, por eso la cultura actual no se eleva lo más mínimo" (Nietzsche, 2010, p. 377).

Una exacerbación semejante del sentido histórico deviene enfermedad histórica: para Nietzsche, hay un uso exacerbado del sentido histórico, asociado a la caracterización de la historia como ciencia objetiva, como conocimiento útil y por lo tanto aprovechable. Dicho uso es peligroso en la medida en que abstrae de la experiencia humana sólo aquello que supone utilidad; privilegia una visión de la vida ocupada en la productividad, y por tanto un ideal de formación saturado de sentido histórico objetivo, en una palabra: enfermo. Prima en todos los aspectos el criterio de utilidad que tasa, sopesa, determina la oportunidad, el beneficio y la explotación de cualquier recurso (del principal de ellos, concreto y real: el tiempo, la vida). Esta concepción, saturada de sentido histórico (enferma por exceso de historia), subordina las distintas dimensiones posibles de la vida y se establece como cultura, como su interpretación hegemónica. 


\section{EI sentido histórico como problema}

En la medida en que trata de hechos acabados, la ciencia histórica pretende para el pasado el valor de conocimiento objetivo: hay una cierta convicción general acerca de la veracidad y el carácter finiquitado de la historia. De acuerdo con Karl Jaspers, un error fundamental de la ciencia histórica es abordar el pasado como un hecho acabado: "La Historia no es un saber intemporalmente válido acerca de algún hecho invariable y acabado, sino que, entendida como saber, varía con el acontecer histórico, concebido como acaecer real" (Jaspers, 1963, p. 348). La historia como ciencia de la memoria, y la fillología como ciencia que interpreta los textos del pasado, no se sustraen a la dinámica de la objetivación; pretenden, como las ciencias naturales, una adecuación a los hechos en la que el observador puede alcanzar un conocimiento completo del objeto. Aquí el objeto es el hecho histórico, el pasado.

Este exacerbamiento y culto del sentido histórico es un hecho cultural determinante en la formación de la juventud. Este problema es el núcleo de la Segunda consideración intempestiva. Un exceso de sentido histórico perjudica la vida y el presente, la valoración del instante como posibilidad concreta de afirmación y creación. La historia como lo que acontece (Geschichte) y arrastra consigo la vida de los hombres y los pueblos, en tanto hecho inexorable y concreto; la historia como saber y conciencia de ese pasado (Historie) y la actitud del hombre frente a lo acontecido, determinan el valor del instante y la medida de valor del presente: "Por consiguiente, debemos considerar el pasado - esta es precisamente la suerte de los hombres: a nadie se le ahorrará estar bajo ese duro yugo (...)-" (Nietzsche, 2010, p. 522). La amplitud inabarcable de nuestro horizonte cultural resulta haciendo tan banal cuanto encontramos en ese horizonte, que al mirar atrás en la historia sólo parece que vemos el camino hasta la "cima" y "progreso" que, se supone, es el presente. Este sentimiento epigonal del último hombre, satisfecho de su evolución, irrefutable, moderno y por lo tanto superior a todo lo pasado (epígono de la Historia), descansa en la convicción de que es la razón lo que se manifiesta en $s u$ Historia.

\section{El carácter intempestivo de esta reflexión}

Nietzsche sintió como perjudicial, como enfermedad y desventaja para el desarrollo pleno de la vida, el exceso de erudición, la acumulación de conocimientos sobre el pasado $\mathrm{y}$, en general, de conocimiento histórico 
objetivo. El sentimiento de superioridad moral de la época, este culto del saber objetivo, reflejan para Nietzsche el carácter negativo y perjudicial que una acumulación desmedida de conocimiento significa para la vida: ya que ésta no es sólo conocimiento, ni puede extraer su fuerza vivificante, ni su sentido, del puro conocimiento "neutral" y "objetivo". La caracterización de este problema como "enfermedad" señala lo que para Nietzsche es un problema esencial para la vida. Como señala Lacoue-Labarthe, un asunto vital, es decir, filosófico: "Filosofar, significa medir o estimar el grado de vitalidad (...) por consiguiente, discriminar lo sano de lo enfermo" (1983, p. 17).

Tal crítica trata de la importancia y valor del conocimiento, su valor para la formación de individualidades libres y fuertes, del aspecto y carácter que dicho conocimiento confiere a la vida y, por tanto, del valor de la vida misma. Esta es una actitud que toma distancia del presente: es intempestiva, inactual e intemporal, sin que ello signifique indiferencia u olvido del presente. Intempestiva es la reflexión que tal contemplación del presente suscita en torno a problemas que pertenecen a todas las épocas. El pensamiento intempestivo no es coyuntural ni contextual, aún si se ocupa de problemas actuales. Nietzsche examina un exceso de sentido histórico que aqueja a su época, pero se ocupa de ello en tanto enferma a la cultura entera y deforma la visión y el significado del pasado, y en la medida en que perjudica el sentido creador, la visión de la humanidad actual y la posibilidad del genio y, con él, del porvenir. La pregunta de Nietzsche por la "utilidad" de la historia no entiende tal utilidad en un sentido pragmático, sino en un sentido intempestivo: ella debería servir como espejo al presente, del mismo modo que las figuras de los genios y héroes dan testimonio de que en todo tiempo son posibles la grandeza y la genialidad. La Historia (Geschichte) debe superar la imitación, la comodidad y el simple afán de actualidad y novedades: "Historia sin imitación (sin someterse a lo grande), sin piedad (sin proteger la atmósfera de lo vivo), sin necesidad actual (...)" (Nietzsche, 2010, p. 524).

El pensamiento intempestivo puede ocuparse de preguntas propias del presente, pero rebasa el horizonte limitado y estrecho de éste, y proyecta el alcance de su reflexión más allá de la mirada actual y de las preocupaciones de la opinión pública. Su ámbito de reflexión es el destino del hombre; en esencia le preocupa la historia sólo en la medida en que ésta prefigura tal destino. Ignora, por tanto, la pequeña política nacional de los diarios y los salones, 
las intrigas de poder y la propaganda, y se ocupa de la "gran política”, ámbito amplio de la creación y enriquecimiento del espíritu. Observa la historia, no en busca del detalle o la objetividad absoluta de los conocimientos históricos, sino de captar del devenir histórico los tipos, las corrientes y fuerzas, es decir, aquello que permanece por sobre toda contingencia: grandeza, belleza, valor. Elude la simple actualidad, toma distancia de las manías, gustos, modas o preocupaciones del presente. Que estas consideraciones sean intempestivas no significa inactualidad, sino que -según Llinares- "(...) apuntan hacia otra cosa más compleja, honda y subversiva, fruto de andar contra la corriente, oponiéndose al tiempo presente" (Nietzsche, 2011, p. 636).

El abarrotamiento de cultura histórica, como todo indigestarse de conocimiento, produce pesadez y permite ahorrarse el pensar en uno mismo. La excesiva preocupación por la actualidad y utilidad, por el aspecto eminentemente utilitario de la vida, no propicia ni hace posible este pensar en uno mismo. Por esto, lo intempestivo es a su vez, lo más raro y escaso. El intempestivo huye a su soledad y desde allí contempla, toma distancia de su propio tiempo, y desde esa distancia valora e interpreta:

Esta consideración es también intempestiva porque yo trato de entender como un daño, como una enfermedad y un defecto de nuestra época algo de lo que ésta está orgullosa con razón, su formación histórica, porque llego incluso a creer que todos sufrimos de una fiebre de consunción histórica y que por lo menos todos deberíamos reconocerlo (...). Este punto tengo, por lo menos, derecho a concedérmelo por mi profesión de filólogo clásico: pues no sé qué sentido podría tener la filología clásica en nuestra época, si no es el de -obrar de forma intempestiva- es decir, contraria al tiempo y, por esto mismo, sobre el tiempo y en favor, así lo espero, de un tiempo futuro (p. 696).

El pensamiento intempestivo es, según lo anterior, contrario al tiempo; subvierte la imagen y el convencimiento que su época tiene acerca de un fenómeno; desconoce así su historia como interpretación determinante, pone en duda los valores hegemónicos y dominantes y es, por tanto, 'ahistórico'. Sobre el tiempo, en la medida en que sus problemas y preguntas son plenamente 'históricas', siendo la historia el escenario de toda idea y acto, aún si aborda y enfrenta problemas que pertenecen al ser del hombre en cualquier época. Y para un tiempo futuro: es pensamiento para el porvenir, se ocupa de un destino, de la aspiración del hombre hacia lo eterno; es, por lo tanto, 'suprahistórico'. Con relación a la condición de Nietzsche como filósofo, a la vez contemporáneo y extemporáneo (intempestivo), Karl Löwith ha señalado que: 
Al afirmarse que Nietzsche es el filósofo «de nuestro tiempo» se tendría que preguntar, en primer lugar, qué era el tiempo para él mismo. Desde el punto de vista de su relación con éste, se deben distinguir tres aspectos: 1. Nietzsche, en cuanto tuvo un destino europeo, fue el primer filósofo de nuestra época. 2. En cuanto filósofo de nuestra época, fue al mismo tiempo contemporáneo y extemporáneo. 3. Como último admirador de la "sabiduría" fue también un amante de la eternidad (1968, p. 265).

Nietzsche reflexiona acerca de la enfermedad histórica de la que está aquejada su propia época, pero contrasta sus observaciones con su concepción de la antigüedad griega, de la época trágica de los griegos. Como filólogo no es objetivista, no busca fijar conocimientos acerca del pasado que incrementen el grado de erudición ni el catálogo interminable de hechos, nombres y fechas que componen la ciencia histórica. No se trata de cultivar una historia estática, erudita y simplemente anticuaria. Ante todo, se debe evitar la historia como simple pasatiempo, como ociosidad. El hombre fuerte conoce la historia antes que nada para transformarla a su vez en acción. En uno de los fragmentos póstumos de la época, afirma: "La historia pertenece a los hombres de acción (...)" (Nietzsche, 2010, p. 499). La historia tiene una labor formativa, este es su papel esencial en la cultura: "La cuestión de la historia en Nietzsche es en primer lugar la cuestión de la cultura histórica (historische Bildung): cultura y formación históricas, educación histórica" (Lacoue-Labarthe, 1983, p. 16).

Lo primero que se subvierte en este ejercicio de pensar el pasado de forma intempestiva es la imagen ideal, anticuaria, que se conserva de éste. El problema para Nietzsche es el contraste vital entre la mirada que obtiene del pasado y su propio tiempo; hacer un diagnóstico de los males de la cultura de su tiempo mediante su comparación con la época trágica de los griegos, y desde allí advertir todo lo que tal descompensación entre vida y cultura implica para el porvenir. De acuerdo con Cano, “(...) con el tema de la 'enfermedad histórica', Nietzsche desea ante todo polemizar con la fragmentación y profunda escisión del hombre moderno en contraposición al mundo griego" (2000, p. 90). No basta una mirada científico-objetiva del mundo; hace falta la visión totalizante, intempestiva: filosófica. Mirada que abarca pasado, presente y futuro, y que posibilita preguntas y observaciones más amplias y distantes, por sobre el horizonte limitado del presente, de la opinión pública, de la moda y de la actualidad: pues los problemas que acucian al hombre son eternos, los mismos en todas las épocas, condiciones materiales, caracteres y culturas. Son problemas de los que se ocupan la filosofía, el arte y la religión. En otro de los fragmentos póstumos se lee: 
"Nosotros afrontamos los problemas inmortales del pueblo -tenemos que liberarnos de los que son momentáneos, temporales. Cuadro de la tarea de la generación filosófica moderna. La exigencia de superarse a sí mismo, es decir, lo saeculare, el espíritu del tiempo" (Nietzsche, 2010, p. 346). La filosofía, según lo anterior, es intempestiva en tanto es pensamiento ocupado en "los problemas importantes del pueblo" y, por tanto, necesita trascender el presente tanto como confrontarlo con el pasado.

\section{La experiencia del tiempo y las dimensiones de la temporalidad}

El hombre es esencialmente un ser histórico: su vida transcurre y se consuma en el plano temporal. La conciencia de tal condición es su rasgo esencial. Como ser temporal y consciente de su temporalidad, el carácter histórico distingue al hombre del animal: a diferencia del animal, el hombre posee conciencia del tiempo y vive en el tiempo: "Observa el rebaño que ante ti desfila apacentándose: no sabe lo que es ayer ni lo que es hoy, corre de un lado a otro, come, descansa, hace la digestión, vuelve a correr, y, así de la mañana a la noche, día tras día, atado a muy poca distancia con su placer y desplacer a la estaca del momento y, por ello, sin melancolía ni hastío" (Nietzsche, 2011, p. 697).

Tanto como la conciencia de esa temporalidad, son necesarias para vivir la inconsciencia, la ignorancia y el olvido del trasfondo irracional, absurdo y cruel de la vida. Memoria y olvido corresponden al mismo fenómeno de la vida como temporalidad: la historicidad. Lo histórico, ahistórico y suprahistórico de la vida no son planos excluyentes; en ellos se manifiesta toda actividad humana, individual o colectiva, toda cultura y acontecer. Nietzsche no pretende fragmentar la experiencia en tres planos separados. La distinción de estas tres dimensiones o elementos permite pensar al hombre en su dimensión temporal completa: como ser histórico, que habita la historia y en ella encuentra su fundamento y horizonte. Pero que permanentemente olvida, destruye y crea y es, por tanto, ahistórico, y que aspira, también, a permanecer, a lo eterno y absoluto, a la trascendencia que en la vida finita no es posible. Por ello, a la vez que histórico y ahistórico, el hombre es suprahistórico.

\section{La dimensión ahistórica de la vida}

El animal es esencialmente ahistórico, dado que el instante presente es su única realidad. No tiene conciencia del tiempo; su aprendizaje es instintivo, 
no consciente del ser temporal. Mientras que para el hombre el instante transcurrido regresa como recuerdo y memoria, para el animal el instante transcurrido desaparece inmediatamente en el olvido:

Pero se asombró también de sí mismo por no poder aprender a olvidar y seguir dependiendo siempre del pasado: por muy lejos y muy rápido que corra, la cadena corre con él. Es un milagro: el instante, que en un suspiro viene y en un suspiro se va, surgiendo de la nada y desapareciendo en la nada, aún retorna, sin embargo, como fantasma y perturba el reposo de algún instante posterior. Constantemente se desprende una hoja del libro del tiempo, se cae y se va flotando -de pronto vuelve flotando, posándose en el regazo del ser humano. Entonces éste dice: "Me acuerdo", y envidia al animal que enseguida se olvida y ve cada instante morir de veras, volver a hundirse en la niebla y la noche y extinguirse para siempre. Vive así el animal en forma ahistórica: pues se funde en el presente como un número, sin que quede restante ninguna extraña fracción, no sabe fingir, no oculta nada y en todo momento aparece por entero como lo que es, por lo que no puede ser en modo alguno más que sincero (p. 696).

En este ser consciente del transcurso del tiempo consiste entonces la conciencia humana; del contraste entre la finitud de la existencia y sus aspiraciones de trascendencia o eternidad. La conciencia temporal es la certeza de la precariedad e insuficiencia de la vida, por lo que el acontecer consciente humano es, siempre, intento de superar este contraste y carencia. La conciencia del paso del tiempo explica el afán, la angustia e incluso la vanidad del acontecer humano.

El hombre es ahistórico ya que su relación con el pasado es hasta cierto punto indiferente, en tanto ignora la historia. Actúa espontáneamente, sin conciencia del carácter histórico de sus actos, condicionados sin embargo por el pasado, por la historia entera que define el horizonte de sus posibilidades. Hay en este actuar un olvido esencial: es su propio pasado lo que siempre se le oculta; no le es posible tener de él conocimiento objetivo, por ejemplo, del origen e historia remota de sus instituciones, valores o prejuicios. Esa ignorancia y olvido esencial del origen es condición de toda posible realización auténtica (arte, creación, invención, ciencia; en una palabra: cultura), y es también la imposibilidad de toda certeza última. El olvido es, a la vez, el terreno de toda posible creación, el permanente "comenzar de cero" en el horizonte de posibilidades del ser cultural; olvido también de la experiencia, su inmanente vacío e imposibilidad de trascender en un incesante transcurrir del que nada permanece. 
En sentido positivo y activo, el ámbito ahistórico es la condición necesaria para la creación y enriquecimiento de la cultura, pues no es posible crear sin, hasta cierto grado, olvidar: "Semeja lo ahistórico una atmósfera envolvente que es la premisa de la vida, extinguiéndose ésta si queda destruida aquélla" (p. 609). No es conservando el pasado y respetando la historia como se hace historia. Acción política, creación artística, toda manifestación de cultura auténtica, reclaman un espacio más allá de las condicionantes históricas (lengua, tradición, casta, religión, condiciones materiales). ¿De qué se es capaz si sólo se respeta y venera la historia? La pura contemplación del pasado proporciona al presente la ilusión de estar dentro de los límites de lo justo, o mejor, de lo que la época considera justo. Actuar de modo ahistórico quiere decir, entonces, superar la historia, traspasar los límites de lo "justo" y lo establecido. Según Vattimo (2002, p. 44), el exceso de historia ofrece al hombre justificación para su condición actual, mientras desestimula la creatividad y la novedad en la vida. Es por ello por lo que el estado de creación y transgresión es ciego, olvida el presente y sus medidas de justicia y corrección, sus advertencias y peligros. Dicho estado es el ámbito necesario para el crecimiento y enriquecimiento de la vida y la cultura: “(...) y sin embargo, este estado -absolutamente ahistórico- es la matriz, no ya de una acción injusta, sino de todas las acciones justas (...)" (Nietzsche, 2011, p. 700).

Por su parte, hay un sentido pasivo y negativo del olvido: una actitud desinteresada, indiferente hacia todo pasado, justificación o análisis de este-a la rumia - con la que en todo caso se asocia esa felicidad animal que contempla y olvida inmediatamente el instante para no tener conciencia de él, de su caducidad, precariedad, finitud, de todos los motivos y actos subyacentes a los ideales, instituciones o convicciones del presente. La existencia casi animal, la del rebaño abstraído del tiempo en el instante inmediato, es extraña a tales problemas. Siendo tan vasto el terreno de la historia y de la cultura, resulta que incluso el conocimiento del hombre comprende siempre un horizonte, en extremo limitado, de lo inconmensurable y abismal (lo ahistórico) de la experiencia humana posible.

\section{El olvido como potencia fundamental de la vida}

Al hombre que contempla el rebaño inconsciente, o al niño jugando en medio de su feliz inocencia, que no conoce el apremio del futuro ni el remordimiento, el espectáculo del olvido completo y feliz le proporciona la ilusión de un vivir desinteresado, despreocupado del tiempo: "Por eso se 
emociona, como si evocase un paraíso perdido, al ver el rebaño paciendo o, en confiada intimidad, al niño que no tiene aún nada pasado que negar y juega por entre las cercas del pasado y del futuro en venturosa ceguera. Y, sin embargo, su juego se le ha de interrumpir: demasiado pronto será sacado del olvido" (p. 697).

Esta contemplación nostálgica es fruto de la constante pugna entre la dimensión histórica del hombre (que preserva en la memoria su pasado), y su dimensión ahistórica. El olvido es una fuerza vital, fuente de nuevos impulsos y permanente disposición a empezar y ser siempre en cierta medida niño: de conservar en cierto grado la inocencia del devenir, y de ser en todo tiempo capaz de renovarse y crecer. Ciertamente, el niño vive una vida de continuo aprendizaje y asombro, desinteresada del futuro y sin cargas del pasado, una constante experiencia del instante. Pero la paulatina toma de conciencia del paso del tiempo y del carácter perecedero de su propia vida, le señala la pérdida de esta inocencia del devenir: "Entonces aprende a conocer la palabra 'érase', ese santo y seña con el que la lucha, el sufrimiento y el hastío acometen al ser humano para recordarle lo que es, en el fondo, su existencia -un imperfectum que jamás llegará a la perfección”- (p. 698).

La conciencia del pasado, del carácter perecedero de todo lo que se conoce y experimenta, es conciencia de la muerte propia y de todo lo que se pierde mientras se vive. 'Érase' designa el destino de toda vivencia, empresa, ilusión o propósito; la conciencia del desvanecimiento del mundo y de la vida en un permanente pasado, se descubre al 'niño-hombre' como su verdadero carácter, como empeño que no se consuma, como imperfectum: constante vivir y experimentar que a cada momento se convierte en pasado irreversible, sólo interrumpido por la muerte; olvido definitivo que arrebata el presente y la conciencia, y hace de la vida esencialmente un hecho imposible de perfeccionar: "Cuando la muerte aporta al fin el anhelado olvido, con él escamotea a la vez el presente y la existencia y, así, imprime su sello sobre aquel conocimiento, que la existencia no es sino un ininterrumpido haber sido, una cosa que vive de negarse y de destruirse a sí misma, de contradecirse a sí misma" (p. 698).

La vida no consiste en lo que es, lo que permanece, sino en lo que permanentemente deja de ser: cada acto consumado e irrepetible. La memoria preserva y conserva, establece condiciones necesarias para la sobrevivencia, códigos de comunicación, lenguaje, leyes y normas que hacen posible la experiencia común. El olvido garantiza al hombre la capacidad de renovarse 
y experimentar, de vivir en el instante y extraer de él su valor. Si no olvidara el sufrimiento y el dolor; si además tuviese una conciencia permanente y total de sus acciones y de los peligros que trae consigo vivir, toda experiencia se le haría imposible. "En toda acción hay olvido: del mismo modo que en la vida de todo ser orgánico hay no solamente luz, sino también oscuridad. Un ser humano que quisiera por entero sentir solamente de forma histórica se parecería a uno que estuviera obligado a prescindir del sueño" (p. 698).

Cada nuevo acontecimiento sería una carga perpetua y el conocimiento de todos los motivos y consecuencias de los actos una objeción en contra de la acción, en contra de la vida. El olvido hace posible crear, amar, afirmarse en la existencia: "Tanto en la mínima felicidad como en la máxima es siempre una sola cosa la que hace que la felicidad sea felicidad: el poder olvidar, o dicho en términos más eruditos, la facultad de sentir de forma ahistórica todo el tiempo de su duración" (p. 698).

Existe un tipo de felicidad en la vida animal, que no concibe el paso del tiempo, el hundimiento de la realidad en el pasado ni la cercanía de la muerte. Esta certeza del ser histórico y mortal, conciencia de la historicidad, es el rasgo esencialmente humano. Por más desinterés que se tenga por la realidad, no es posible sustraerse a la conciencia del paso del tiempo, al desenvolvimiento de la vida que se consuma continuamente. Desinterés e indiferencia constituyen una forma de felicidad, un estado ahistórico muy cercano a la felicidad animal. El olvido tiene en la vida una importancia de orden superior, pues de la capacidad de olvidar depende la de afrontar la historia vivida, que deviene y en la que el hombre y su época transcurren, escenario de sus empeños, luchas e ilusiones; historia que nos ocurre con sucesos felices y dolorosos, con grandes gestas y tragedias. El olvido pertenece al ser ahistórico, es la parte de la vida que no está sujeta al pasado, limitada o cercenada por éste y por lo tanto imposibilitada para crecer, actuar y decidir. Al contrario, el hombre o la época cautivos del pasado encadenan a éste su presente y futuro:

Llamémosles los seres humanos históricos: la mirada fija en el pasado los empuja hacia el futuro, los alienta a continuar luchando con la vida y enciende en ellos la esperanza de que lo bueno todavía vendrá, de que la felicidad está detrás de la montaña que se aprestan a escalar. Estos seres humanos históricos creen que el sentido de la existencia se revelará cada vez más claramente en el curso de un proceso (...) no saben que pese a toda su historia piensan y actúan en forma ahistórica y que su misma ocupación con la Historia no está al servicio del conocimiento puro, sino de la vida (p. 701). 
La vida del hombre ocurre entre el olvido y la memoria: sufre porque no puede recordar, o porque no puede olvidar. Los mismos hechos, que en un momento le llenan de placer y orgullo, más tarde tal vez le ocasionan arrepentimiento y dolor. Hay certezas que, firmes en el pasado, a la luz del presente aparecen desnudas en su realidad. Como en la vida individual los hombres cambian permanentemente sus perspectivas e intereses, su horizonte cultural muda de convicciones y verdades. Para vivir se requiere fuerza plástica, capacidad de olvidar: hay naturalezas capaces de cicatrizar, sanar, olvidar y soportar los embates de la vida, los golpes más crueles y amargos. Por el contrario, las hay incapaces de olvidar el menor daño o afrenta; ante una humillación, derrota o traición, revelan la debilidad de su carácter. Estas naturalezas, que nunca olvidan, sufren siempre. La capacidad de recordar no es necesariamente una ventaja, pues conlleva dolor. La creación auténtica y el acto libre son posibles sólo si hay ruptura con el pasado y el presente, mediante una ignorancia y olvido esenciales de la historia, y en favor de una praxis creadora: "En consecuencia: es posible vivir, y aun vivir feliz, casi sin recordar, como lo muestra el animal; pero es totalmente imposible vivir sin olvidar" (p. 698). Es necesaria, entonces, la capacidad de olvidar y de conservar sólo aquello que sirve a los propósitos de la vida. Esta fuerza vital se manifiesta como poder de interpretación y transfiguración del pasado: "Esa fuerza plástica es, en definitiva, la fuerza interpretativa y creadora del mundo entorno, sin la que no se podría vivir y la que convierte ese mundo en un mundo histórico" (De Santiago Guervós, 2005, p. 111).

En términos de conservación de la memoria, valga decir en términos historicistas, no conocemos hechos concretos y objetivos del pasado, sino interpretaciones de los testimonios y de las evidencias de los hechos mismos. Todo conocer histórico es mediato: hay en todo momento de la historia narrada, de la reconstrucción escrita de los acontecimientos, un acto interpretativo. Todo pasado depende, por tanto, del presente en que dicho pasado se investiga, narra e interpreta, de forma tal que mientras escribe su historia el hombre se transforma a sí mismo en el acto de dar forma a su pasado, olvidando y transformando el sentido de aquellos hechos en la forma en que lo requiere su vida. Esta especie de transfiguración estética se lleva a cabo en la conciencia individual y colectiva, cuando se fija el pasado de acuerdo con una concepción, con una interpretación predominante del mundo y la vida. El hombre habita un mundo estético, un universo de simulaciones en el que su vida se desarrolla y del que obtiene fuerza, sentido 
y fundamento; una 'ilusión necesaria', un horizonte de interpretación en que cada fenómeno tiene su historia y por lo tanto su significado. El sentido histórico es tan importante para la vida como el olvido; memoria y olvido son manifestaciones complementarias de la historicidad, rasgo esencial de lo humano: "Tal es precisamente la tesis que el lector está invitado a considerar: lo ahistórico y lo histórico son por igual necesarios para la salud de los individuos, de los pueblos y de las culturas" (Nietzsche, 2011, p. 699).

\section{La dimensión suprahistórica de la vida}

Finalmente, la vida posee un elemento 'suprahistórico' al que pertenecen las aspiraciones del hombre hacia lo eterno, absoluto e intemporal. Como lo 'suprahistórico' podríamos referirnos en general a esa dimensión de la vida en la que el hombre alberga sus ilusiones eternas: éstas comprenden necesidades, anhelos, temores y pasiones que le acompañan en toda época. El punto de vista suprahistórico observa la historia, pero, contrario al punto de vista histórico no ve en ella una necesidad, es decir, el camino hacia una meta. Comprende que todas las visiones de mundo imperantes a lo largo de la historia han perecido porque sus convicciones eran ilusiones necesarias. Es por ello que las carencias y necesidades humanas permanecen aún si las condiciones materiales y culturales cambian:

Cabría calificar tal punto de vista de suprahistórico, porque el que lo adoptara ya no podría experimentar ninguna seducción para seguir viviendo y cooperar en la Historia, por haber captado la única condición de todo acontecer, esa ceguera e injusticia en el alma del agente; todavía más, desde entonces se habría curado de tomar demasiado en serio la historia; pues habría aprendido a extraer de cada ser humano, de cada vivencia, así se refiera a griegos o a turcos, de una hora del siglo I o del siglo XIX, la respuesta a la pregunta de cómo y para qué se vive (p. 701).

La contemplación de la vida en su elemento suprahistórico entiende los sistemas absolutos de creencias y las fundamentaciones de sentido como interpretaciones y ficciones, como ilusiones necesarias para vivir. Contrario al sentido histórico, no concede a la historia el valor de objetividad y verdad que justifica la existencia tal como es, ni concibe un progreso de la humanidad hacia algo mejor. Si como hemos señalado, la dimensión suprahistórica de la existencia alberga los anhelos del hombre hacia lo eterno y lo superior, esto significa que a través de lo suprahistórico el hombre busca trascender la historia. 
Lo histórico por excelencia es la vida finita del hombre. En ella se consuman las corrientes de la Historia (Geschichte) y de la cultura, y el espíritu concibe sus obras y monumentos para el porvenir. En la vida individual la humanidad lucha, establece valores, ejecuta ideas. Sin embargo, la finitud y el perecer de toda existencia individual, y la conciencia de esa finitud, infunden en el hombre la aspiración de trascender. Pero no hay trascendencia posible para el hombre en el ámbito natural: todo propósito o ilusión chocan con la final certeza de la muerte, de la finitud que hace de toda vida un proyecto en permanente consumación; un imperfectum que ante la imposibilidad de la realización total, posee apenas la aspiración permanente hacia esa realización. De ahí que la necesidad inherente de la conciencia humana por trascender sea posible únicamente como cultura: arte, sentimiento religioso, filosofía. Son estas potencias las que aspiran a alcanzar tipos superiores y eternos, y aspiran a la constatación de que éstos son posibles en todo momento de la historia:

Con el término 'lo ahistórico' designo el arte y la fuerza de poder olvidar y encerrarse dentro de un horizonte limitado; llamo 'suprahistóricas' a las potencias que desvían la mirada del devenir y la dirigen hacia aquello que confiere a la existencia el carácter de lo eterno e inalterable, hacia el arte y la religión. La ciencia -que es la que hablaría de venenos- ve en esa fuerza y en esas potencias, fuerzas y potencias enemigas, pues sólo reputa verdadera y justa, es decir, científica la consideración de las cosas que ve en todas partes algo devenido, algo histórico, y en parte alguna un ente, un algo eterno; vive en íntima contradicción con las potencias eternizantes del arte y de a religión, del mismo modo que odia el olvido, la muerte del saber, y trata de anular todo lo que limita el horizonte y proyecta al ser humano en un mar infinitamente ilimitado, de ondas de luz del devenir conocido (p. 746).

\section{La cultura como vivencia de la historia}

Se han distinguido, hasta ahora, tres dimensiones de la temporalidad humana. Queda dicho que el planteamiento de estas tres dimensiones o elementos de la temporalidad no pretende una escisión o fragmentación de la experiencia. Es posible identificar en la vida del hombre: una dimensión histórica, en la medida en que es la historia lo que determina su horizonte vital; una dimensión ahistórica, como el elemento irracional y abismal de la experiencia, más allá de todo sentido e interpretación; finalmente, una dimensión suprahistórica que aspira a trascender la historia.

La Segunda consideración intempestiva muestra la interpretación nietzscheana del problema de la historicidad como fenómeno esencial de la 
naturaleza del hombre y, a su vez, como determinante de la cultura, entendida como la entera concepción del mundo propia de un pueblo. Hemos señalado antes que la cultura es, en términos generales, una ilusión necesaria, ficción e interpretación del mundo desde donde los hombres afrontan el hecho de su finitud histórica. Esto quiere decir que la cultura contiene en sí los elementos con los cuales la conciencia dota de sentido a la vida: creencias, convicciones, valores estéticos que confieren a la experiencia de vivir en el tiempo una cierta y específica unicidad de sentido. Cultura es el fenómeno característico de un pueblo, su manifestación más particular y esencial: "La cultura de un pueblo como antítesis de esa barbarie ha sido definida en cierta ocasión, tengo entendido que con cierta razón, como unidad del estilo artístico en todas las manifestaciones vitales de ese pueblo" (p. 713).

Lo que aquí se denomina cultura no tiene nada que ver con un concepto artificial o demagógico de la cultura; se refiere, en cambio, a la manifestación del carácter de la vida entendida como el relacionarse del hombre con su historia, al modo en que asume su propia historicidad: la historia es la propia vida, tanto en lo que conserva de ella la memoria, como en lo que olvida. La vida es un fenómeno esencialmente histórico; esto es evidente por cuanto sólo se existe en el tiempo. Todo ente pensado o intuido que esté al margen de la historia (ahistórico, suprahistórico) es primero una intuición temporal, histórica (porque toda conciencia, así como todo producto de la conciencia, es temporal). Pues quien intuye la divinidad, la eternidad, el universo infinito, el tiempo y la muerte (en que cesa la historia), es siempre un ser concreto, mortal, temporal e histórico. La historia como vivencia (Geschichte) es un hecho evidente y fundamental. La Historia como memoria (Historie) es en sí misma la evidencia de este hecho fundamental: sólo el hombre es histórico, en la naturaleza y universo infinitos en que todo retorna eternamente. Sólo la conciencia es fugaz, porque es conciencia de la fugacidad misma, porque se entiende a sí misma temporal, finita y perecedera.

La cultura es, por tanto, manifestación de la civilización que la produce. Nietzsche advierte cómo, incluso, es posible pertenecer a una civilización sin por ello tener, necesariamente, una cultura auténtica: "Nosotros no tenemos cultura, sino una civilización con algunas modas culturales, pero más que otra cosa barbarie" (Nietzsche, 2010, p. 478). Una cultura enferma es síntoma de una enfermedad mayor, generalizada, la enfermedad de la civilización entera. ¿Qué dice la cultura de un hombre acerca de su condición? No una noción libresca de la cultura (leer libros o ir a conciertos y museos), sino su entero 
'modo de ser': lenguaje, gestos, ideas o intereses y, en general, su forma de reaccionar y de relacionarse, manifestación de su condición espiritual. Del mismo modo, la cultura de un pueblo manifiesta su salud interna. El problema de la cultura es que la vida posea valor. La ausencia de cultura auténtica, la imitación y veneración de formas pasadas o foráneas, de interpretaciones inauténticas, denota ausencia de identidad, repetición de los mismos tipos e ideas, conformismo.

\section{Conclusión}

De acuerdo con lo expuesto hasta ahora, el exceso de conocimiento histórico perjudica la vida cuando se convierte en culto y perpetuación del pasado en detrimento del presente; cuando anula los elementos creativos y favorece la actitud pasiva e indiferente hacia la propia realidad. Una cultura puramente imitativa y repetitiva es síntoma de una existencia conformista, de la que está ausente todo aquello que aspira en el hombre a lo superior, a la belleza, a la nobleza y al valor; en fin, a todo elemento creativo y auténticamente liberador del peso de lo histórico. La utilidad como valor hegemónico determina todos los planos de la vida: la temporalidad en primer lugar, en tanto el tiempo es medido, calculado, controlado y administrado. La lógica de la utilidad, por tanto, privilegia el sentido de lo histórico para el que toda acción humana obedece a un propósito y hace parte de un determinado fin, y todo hecho y realidad histórica posee entonces derecho y razón. Es una lógica de la total utilidad de las personas y de su explotación. El exceso de sentido histórico perpetúa la realidad histórica, a la vez que neutraliza y suprime el elemento irracional, ahistórico y eminentemente creador.

La experiencia contiene en sí tres dimensiones. Una escisión excluyente en favor de una de ellas, o mejor, en detrimento de las restantes, implica un empobrecimiento general de la vida. La cultura en sí misma es una manifestación de estos tres aspectos de la vida y del valor que cada pueblo les confiere, con lo que cada una aporta al enriquecimiento de la experiencia vital: una dimensión histórica en la que se manifiesta la vivencia concreta; una dimensión ahistórica, terreno necesario de la creación, del pensamiento, el arte y la acción; y una suprahistórica, dimensión de la eternidad y trascendencia. Y sin embargo, toda exacerbación de alguna de las dimensiones de la historicidad, en cuanto suprime o niega valor a las demás, niega al pensamiento su posible plenitud. 
Al final, lo que tiene importancia es el modo en que la propia historicidad se asume: un carácter de la vida puede ser dominante sobre los otros. Así, cuando domina el carácter ahistórico y el hombre es indiferente a la historia y a la trascendencia, su vida es una sucesión de actos reflejos, sin reflexión ni preguntas que cuestionen la existencia; la inconsciencia gobierna la mayor parte de la vida, el olvido y el sueño prevalecen sobre la memoria y la consciencia. Si es eminentemente histórico, vive empeñado en su transcurrir, en la marcha del mundo material; se empeña cada día en su ser temporal, al punto que confunde su ser histórico con su ser entero. El suprahistórico, a su vez, aspira al 'más allá', a trascender y derrotar a la muerte como idea, como arte o como Dios. Sin embargo, la aspiración ciega hacia el más allá, en detrimento de la historia viva o del instinto de crear, empobrece la vida.

La vida del animal es ahistórica porque al tiempo que vive, olvida. El ser histórico, el hombre, no olvida el hecho de que va a morir; a lo sumo ignora esta certeza deliberadamente, la aplaza. En esto consiste su vanidad: toda su vida de apariencia es una lucha con la conciencia de ese hecho, el más incierto y a la vez el único cierto. El ser suprahistórico se trasciende a sí mismo justamente con ese fin: quiere superarlo creando o creyendo. Pero el hombre consciente, vive en sí la agonía (la lucha) entre sus instintos fundamentales, entre los modos de su historicidad, y los sintetiza en su propia experiencia. La filosofía como modo de vivir intempestivo, constituye por lo tanto una cierta sintesis vital entre las dimensiones de la vida: consciente de su finitud, de su carácter suprahistórico y de su necesidad y posibilidad de trascender. Y por ello mismo, de su ser ahistórico: no hay vida consciente en la entera sujeción y veneración del pasado. En la vida, el arte, la cultura o la acción política, se requiere siempre un grado de olvido y de inconsciencia, como el organismo necesita siempre del sueño. El pensar (y el vivir) filosófico, en la medida que es intempestivo, supera la sujeción al presente (siempre imperfectum, siempre inacabado; detrás de sí subyacen el silencio, la ignorancia, la indiferencia del universo vasto y silencioso). Pero tampoco hay consciencia posible en el desconocimiento de la propia historia, propiciado por una sociedad que elabora y disemina un discurso vulgar e igualitario del pasado, y que a la vez reprime el auténtico aliento creador y la necesidad de superar la propia vida cotidiana del trabajo, el placer y la necesidad, pues la vida necesita olvidar tanto como necesita recordar, tanto como necesita trascender. 


\section{Referencias}

Cano, G. (2000). Como un ángel frío. Nietzsche y el cuidado de la libertad. Valencia: Pre-Textos.

De Santiago Guervós, L. E. (2005). Arte e historia en F. Nietzsche: ¿Una estética de la historia? Contrastes. Revista Internacional de Filosofía, 10 (1), pp. 100-117. https://doi.org/10.24310/Contrastescontrastes. v0i0.1884

Heidegger, M. (2012). Ser y tiempo. Madrid: Trotta.

Jaspers, K. (1963). Nietzsche. Introducción a la comprensión de su filosofar. Buenos Aires: Sudamericana.

Lacoue-Labarthe, P. (1983). Historia y mimesis. Instantes y azares. Escrituras nietzscheanas, 6-7, pp. 15-38. https://www.instantesyazares.com.ar/ article/historia-y-mimesis/

Löwith, K. (1968). De Hegel a Nietzsche. Buenos Aires: Sudamericana.

Nietzsche, F. (1967). Digitale Kritische Gesamtausgabe Werke und Briefe. Berlin / New York: Walter de Gruyter.

Nietzsche, F. (2010). Fragmentos póstumos. Volumen I (1869-1874). Madrid: Tecnos.

Nietzsche, F. (2011). Obras completas. Volumen I. Escritos de juventud Madrid: Tecnos.

Nietzsche, F. (2013). Obras completas. Volumen II. Escritos filológicos. Madrid: Tecnos.

Sánchez Meca, D. (2013). Nietzsche. La experiencia dionisíaca del mundo. Madrid: Tecnos.

Vattimo, G. (1984). Introducción a Nietzsche. Barcelona: Península.

Vattimo, G. (2002). Diálogo con Nietzsche. Barcelona: Paidós. 